\title{
Visual cues and innovation adoption among bottom of the pyramid consumers
}

\begin{abstract}
Purpose - To explore how visual comprehensibility of a product can affect innovation adoption among bottom of the pyramid consumers (BOP) in Bangladesh.

Design/methodology/approach - This is an exploratory qualitative study based on interviews with 8 managerial respondents involved in the design and marketing of innovative products targeted at BOP consumers in Bangladesh, and 3 respondents who are consumers of these products.
\end{abstract}

Findings - One key finding from this research, in comparison to innovation adoption research in developed contexts, is the distinct importance that BOP consumers attach to visual cues in learning about and understanding a new product.

Practical implications - This research provides guidance for private and public sector organisations selling products and services to BOP consumers on the role of visual cues in generating better product comprehension. It also identifies the role of social relations in facilitating adoption of new products within this segment.

Social implications - Through enhancing adoption of so called pro-poor innovations this research can assist in bringing about positive social change and developmental benefits in this burgeoning segment of the market.

Originality/value - This is one of the first studies to consider innovation adoption of propoor innovations in BOP markets and one of the first studies to collect data on the role of visual comprehensibility for consumers in BOP markets.

Keywords Visual cue, visual comprehensibility, Innovation adoption, Bottom of the Pyramid, Low-literacy, Poverty, Poor, New product, Adoption, Emerging Market

Paper type Research paper. 


\section{Introduction:}

In the context of the developing world the marginalised and poor have gained new significance and are a focus for marketers owing to Prahalad's (2010) seminal work on Bottom of the Pyramid (BOP) consumers. Prahalad identified this segment of consumers as the 4-5 billion poor consumers of the world who are underserved or not served by the large organised private sector, including multinational firms (Prahalad, 2010). The BOP market is an attractive U.S. \$5 trillion global market, the overwhelming majority of which lives in nonWestern (and mostly developing) countries (World Resources Institute, 2007).

BOP consumers vary across the world in terms of their income, educational qualifications, gender, rural-urban mix, culture and religious differences. Based on recent data (CIA, 2013), this market is growing rapidly due to increasing development and growth in developing countries like Mexico, Bolivia, Bangladesh and Ivory Coast (Payaud, 2014), where large segments of the market reside.

The BOP is dramatically different from the middle and high income consumer market because of unreliable electricity, infrastructural challenges, political instability, economic constraints (e.g., low GDP, high inflation) and a low literacy rate (Prahalad, 2005; Rogers, 2003; Nwanko, 2000; Johnson et al., 2007; Eifert et al., 2005). Products must, therefore, be developed that are tailored for this market and its unique surroundings (e.g., economic constraints, unreliable electricity etc.). Increasingly, there segments of BOP customers with diverse needs, which are not well served within many categories, although this is changing as organisations are realising its economic potential. This raises some interesting questions about how organisations can begin to satisfy consumer needs more readily, and create product offerings, which will be accepted in this marketplace. Whilst a good deal of literature offers insight about new product acceptance in developed economies in Europe, Japan, the 
United States, and the United Kingdom (e.g., Shih and Venkatesh, 2004; Plouffe, Vandenbosch, and Hulland, 2001), research on BOP markets and the developing context is much more sparse within the literature, presumably because of the less recognised economic importance of such markets in the past. Current research in the area of innovation adoption has yielded many competing models (e.g., The Technology Acceptance Model, Davis 1989; the Theory of Reasoned Action, Fishbein and Ajzen 1975; Diffusion of Innovations, Rogers 2003), each with different sets of innovation acceptance determinants. Visual comprehensibility is one of these determinants and represents the degree to which an innovation is intuitively comprehended by BOP consumers through its design and packaging. Increased visual comprehnsibility should assist BOP consumers to understand a product better in light of lower literacy rates. However, as yet, though identified in some research as an important factor in the BOP market (i.e., Nakata and Weidner, 2012), no research has explored this phenomenon based on data collection in BOP markets. To address this gap in the literature, this paper aims to explore how visual cues can enhance visual comprehensibility of a product and can affect innovation adoption among BOP consumers in Bangladesh. In doing so, it contributes to the literature on innovation adoption in the BOP through the development of insights about the role and nature of visual comprehensibility in influencing take up of pro-poor innovations.

\section{Literature review:}

In the literature, several models have been put forward to explain consumer adoption of new products, and these typically focus on cognitive evaluations. Generally, the majority of the research is built upon the Technology Acceptance Model (TAM, Davis 1989), Rogers' (2003) Diffusion of Innovations (DOI), or the Theory of Reasoned Action (TRA, Fishbein and Ajzen 1975). In the innovation adoption literature, perceived attributes of the innovation and characteristics of the adopter are found to be the main drivers of innovation adoption 
(Rogers, 2003; Meuter, Bitner, Ostrom, and Brown, 2005; Gatignon and Robertson, 1985; Tornatzky and Klein, 1982). Adopter characteristics represent the personal traits that explain the adopter of an innovation, including psychographics and socio-demographics. Researchers have used a wide variety of socio-demographics characteristics in previous research (e.g., Gatignon and Robertson, 1985; Rogers, 2003). Some of these specifically focus on level of education, consumers' age, and income. Other variables that are considered often include gender, household size, and family life cycle. However, it seems that psychographic characteristics remain the most useful predictors of innovation adoption based on one recent meta-analysis in the area (Arts et al., 2011). Typical psychographic characteristics include innovativeness, media proneness, opinion leadership, and involvement (see, for example, Lowe and Alpert, 2015). In addition, innovation attributes, one of the major drivers of innovation adoption, refer to the characteristics consumers utilise to evaluate an innovation and these are normally presented by a consumer's perception of the relative advantage, complexity, compatibility, trialability, observability (Rogers, 2003) and risk or uncertainty (Ostlund, 1974; Hoeffler, 2003) of the innovation.

The innovation adoption literature focuses on characteristics of the adopter and perceived attributes of the innovation. However, BOP consumers are often characterised as low-literate, and with limited numeracy skills (Prahalad, 2010; Nakata and Weidner, 2012; Nwanko, 2000; Johnson et al., 2007). Consequently, visual comprehensibility, or the degree to which an innovation is intuitively comprehended by BOP consumers through its design and packaging (e.g., colours, shapes, logo, photos, physical package size, and other elements of product package) is likely to be important for innovation adoption in the BOP context. Though this has been hypothesised in prior research (e.g., Nakata and Weidner, 2012) observations about visual comprehensibility in this market segment are sparse. Prior studies in developed country contexts have shown that some consumers are more likely to process 
information visually (Heckler et al., 1993). This theme, which recognises the importance of the visual aspects of a product, has become more common with research on innovation adoption (Crilly, Moultrie and Clarkson, 2004). Other research in the BOP has begun to recognise the importance of visual meaning too (Chikweche and Fletcher, 2011). In a consumer context, it is expected that those with a high visual orientation are more likely to find it easier to use any product and service because they can visualise it better than those who are low in visual orrientation (Bruner and Kumar, 2005). However, a visual orientation is more prone amongst illiterate consumers who are less familiar with text and the alphabet (Havelock, 1978). Prior research has also found that visual style processing infuences perceived ease of use of an innovation (Bruner and Kumar, 2005), although this research was conducted on consumers in developed contexts. One example is that consumers with a low level of literacy may use one aspect of a product (such as price, size, ingredients etc.) as a proxy to infer value instead of interpreting price per weight statements written on the package (Viswanathan et al., 2005). For example, given a certain price then such a consumer may use attributes like weight or size to determine if that product is good value, rather than more carefully evaluating it as a bundle of attributes. Therefore, due to information processing constraints (e.g., low literacy), BOP consumers may use visual cues such as colours, shapes, logos, photos, physical package size, and other elements of a product's package to undertand the value of that product. These consumers exhibit a greater reliance on visual cues (Viswanathan et al., 2005), and such cues thus become more important in enhancing comprehension of a product and providing messages that consumers understand better.

In addition, there might be a large distance between BOP customers and companies economically, culturally and geographically. To some, these causes/products may be unheard of in some rural areas and companies have to first educate consumers about product benefits to influence adoption. Visual cues can enhance visual comprehensibility and are likely to help 
low-literate BOP consumers to more easily understand the benefits of new and unfamiliar products and services. Given the importance of visual comprehensibility, it is surprising that there has been very little work in identifying ways in which visual comprehensibility can affect adoption. In this research, visual comprehensibility was explored in an effort to understand its relationship to adoption better.

\section{Research context:}

Bangladesh was chosen as the research context for this study as it has large segments of BOP consumers. It has also been used as a research context in other BOP studies too (e.g., Rahman et al., 2013) because it is congruent with Prahalad's (2010) assertions about the BOP. For instance, $31.5 \%$ of the population of Bangladesh were under the national poverty line during 2010 (World Bank website, 2013). Another reason for choosing Bangladesh for the study was that the country has primarily concentrated on innovations related to infrastructure and social development recently. Some innovations like sanitary latrines, mobile banking, and community information centres are diffusing among the BOP population of Bangladesh. As this research is about visual comprehensibility and innovation adoption, choosing a country like Bangladesh, which primarily focuses on innovations in different sectors, is very relevant. In addition, the researcher is familiar with Bangladesh, its culture, and language (i.e., Bengali, the national language of the country).

\section{Qualitative methodology:}

The overall methodology of this paper is based on exploratory qualitative research given the under-explored character of the topic and lack of empirical research on visual comprehensibility in the BOP context (Touzani, Fatma and Mouna-Meriem, 2015). Exploratory qualitative research provides insights to the researcher when there is a limited knowledge of the subject matter (Zikmund et al., 2014). It is useful where the subject matter 
of the study cannot be measured in quantitative terms or where the quantitative measurement does not provide a realistic picture of the subject matter. Exploratory research can also be useful in defining the problem more precisely, identifying the relevant cause-and-effect related course of action, or gaining insight before proceeding with conclusive research. In such circumstances, information required in the exploratory stage will be loosely defined by using open ended (very often) research questions rather than specific hypotheses or by actual measurement (Blumberg, Cooper and Schindler, 2014; Denzin and Lincoln, 2005).

Semi-structured interviews were conducted with respondent groups (Table 1) to gain an understanding of the topic, similar to other recent research with similar objectives (e.g., Dowell, Heffernan and Morrison, 2013; Lowe, Lynch and Lowe, 2014). If one takes a loosely structured and evolutionary approach, for example, personal interviews with industry experts are appropriate. Meticulous and rigorous sampling procedures are not so important here. What is more important in this case is the selection of the right and 'quality' skilful moderator and participants who are willing to open up their imagination, be creative and reveal perhaps sensitive pieces of information, thoughts and behaviour about a subject, object or issue (Malhotra, 2004). One of the authors acted as interviewer himself in this study and was fluent in English, and Bengali, the national language of Bangladesh.

An exploratory study may take the researcher one step closer to conducting conclusive research as a follow up investigation. Exploratory research helps to provide qualitative data full of rich insights. A researcher may search for quantitative information in the study but it does not have to involve rigorous mathematical analyses. Most exploratory research is not quantitative. Applied qualitative research often uses thematic analysis (Braun and Clarke, 2006), which is especially well matched to this research. Consistent with key recommendations in the literature, thematic analysis was utilised to identify, analyse, and report key themes in the data (Braun and Clarke, 2006; Boyatzis, 1998; Frith and Gleeson, 
2004; Hayes, 2000; Sayre, 2001). Initially, the entire data set was read and summarised. Then, the summaries were reviewed by identifying patterns that could form themes as well as codes of analysis. As this research utilised inductive thematic analysis, the process of coding the data was data driven, where the quotes were positioned under thematic headings. Therefore, the themes of this research are based on what was derived from the data.

\section{Respondent groups:}

Interviews were conducted with management, consultants, entrepreneurs and BOP consumers who have knowledge about the products or innovations aimed at the BOP market in the context of Bangladesh. They were chosen based on convenience and the acquaintance of the respondents with the interviewer. Respondents' basic characteristics are highlighted in Table 1.

\section{[Approximate Position of Table 1]}

Discussion within the interviews explored a range of themes but centred around respondents' knowledge of the product or innovation, their attitudes and beliefs about the products, how they visualised the attributes of the product and the ways in which different attibutes of the products affected their understanding of the products, with particular references to its visual aspects. Prompting and probing facilitated the conduct of the interviews making way for useful information for analysis later on. Each interview lasted about 30 minutes and was recorded (except 1 interviewee, who did not want to be recorded and in this case detailed notes were transcribed). Indicative interview questions are provided in Table 2. These guidelines represent themes that were covered but questioning was flexible throughout the interviews. 


\section{[Approximate Position of Table 2]}

\section{Key findings:}

\section{Inter-generational transfer of meaning}

A large number of BOP consumers have reading and writing difficulty because of a higher illiteracy rate in the BOP context. These consumers typically rely on their children or other family members for help in understanding what is written on products. The Head of Fixed Broadband Internet and Broadband Commercial Division (R2) of a telecom company mentioned: “They (BOP consumers) take help from next generations (like school going sons or daughters) for reading and writing something during computer usage in the Community Information Centre.” Similarly, the Junior Consultant (R8) of information service centres also mentioned: “To address reading and writing difficulty of BOP consumers, we promote our information service centre through TV advertisement and projector.” Deputy General Manager (R6) of an insurance company of Bangladesh commented on the reading and writing difficulty of BOP consumers in a similar way: "Some of them (BOP consumers) take help from family members, who went to primary school." It can be understood from the responses of interviewees that BOP consumers have reading and writing difficulties, as many of them are illiterate. Therefore, BOP consumers, who have reading and writing difficulty, need to seek help from others to understand the written information of a product. However, symbols, shapes, photos, and shapes of a product can assist with this issue, and can help BOP consumers to better understand the product. Marketers thus may have to target the literate member in the family to communicate messages to the illiterate BOP target. Thus the conceptualisation of the target audience, media channels and message delivery with the incorporation of social influence may have to take a modified approach to enhance marketing effectiveness. 


\section{Semiotics and the added importance of visual cues for the BOP}

Nakata and Weidner (2012) mentioned that BOP consumers attach literal, concrete meaning to colours, shapes and photos. From the interviews conducted, many of the respondents' answers were consistent with the work of Nakata and Weidner (2012). One consumer (R11) of a mobile banking company mentioned that he had reading and writing difficulty and he used to recognise the outlet of this mobile banking company by their pink coloured bird symbol logo. He mentioned: "I recognise by the bird symbol of

Similarly, a customer (R10) of an information service centre mentioned: "I recognise the information service centre by their logo.” Likewise, a Junior Consultant (R8) of the information service centre mentioned: “They (BOP consumers) can recognise any information service centre by the logo in the sign board.” In addition, the Deputy General Manager (R6) of an insurance company mentioned that their company has a logo and BOP consumers recognise their service by this logo, reinforcing: "Yes. They recognise our insurance company by our logo.” Interestingly, he (R6) also mentioned that their insurance company uses different coloured paper to address the reading and writing difficulty of BOP consumers, stating "We also use different coloured papers or forms so that they can identify or understand the purposes of different papers or forms.” Although BOP consumers have difficulty reading and writing they understand the English numeric digits of mobile phones. The interviewer asked questions to understand how BOP consumers abstract information from the English numeric digits. One entrepreneur (R7) mentioned that: "Farmers, who have no education, can recognise the numeric digits as symbols.” A Senior Officer (R4) of a mobile banking company elaborated on this by mentioning: "Illiterate people can understand pictures, symbols, shapes, and they try to recognise numeric digits as different symbols and attach meanings to those symbols instead of understanding information from them.” 
Therefore, the quotes above imply BOP consumers, who lack basic education, and are often illiterate, place a great deal of emphasis on the meaning and associations from a logo through its symbols, colours, etc. Different colours, symbols and pictures integrated into product communications help BOP consumers to better recognise and understand the product and this may lead to improved adoption later, because the learning process is simpler and more efficient. For example, as pointed out by Hammond and Prahalad (2004), Prodem FFP, a Bolivian firm, developed an automated teller machine (ATM) that recognises finger prints, making it simple and easy for the BOP consumers to use it. It also translates text to speech and displays a colour-coded touch screen (Hammond and Prahalad, 2004).

\section{Localisation of language for the low-literate}

Integrating any product information in a local language in the product package or during the service can help low-literate BOP consumers to understand the product. One customer (R10) of an information service centre mentioned: “Although for the illiterate it is the same, lowliterate people can benefit if the service or product integrates Bengali language.” Similarly, another consumer (R11) of a mobile banking company mentioned: "It could be easier for low-literate people to understand the product if the SMS are in Bangla language.” (which, it should be noted is the national language of Bangladesh). An entrepreneur (R7) also mentioned the importance of integrating the local language in products for farmers "who have no option but to take help from friends and family members to understand the English SMS. SMS in English language only is sent to them because all mobile phones don't support Bengali language. SMS in Bengali language will help the low-literate people to understand the service a lot better.” It is understood from the above mentioned extract of interviews that product benefits are better comprehended by low-literate BOP consumers when the local language is integrated in product packaging, the service environment and marketing communications. 


\section{Ethical practices and signalling authenticity}

A General Manager (R5) of a food product company also mentioned that BOP consumers try to recognise brands by the logo and symbolic interpretation of brand name instead of understanding more explicit textual information from them. He provided an example that sometimes consumers of their company also get confused by a different brand name with a similar looking logo and package; some duplicate (fake) brands use similar colour combinations or similar shapes in their packaging, which confuses illiterate people. In addition, the Head of Marketing (R1) of a toiletries company mentioned the importance of visual cues for BOP consumers by mentioning: “A large part of BOP consumers is illiterate and they only understand colour combination, pictures, and shapes. Visual cue is very important to them. If they (BOP consumers) see any visual cue.... for example fairness cream is improving skin fairness on TV commercial...then they will go for it”. A lack of education may make them more susceptible to messages with ambiguous meaning, reinforcing the need for ethical practices and the need for signs of authenticity in such markets where intellectual property is harder to enforce (Sey, Lowe and Poole, 2010).

\section{Discussion and Implications:}

The paper provides some exploratory observations on how logos, symbols, different colour combinations and other visual aspects of a product help BOP consumers to understand or recognise the product/service better. As BOP consumers face a number of information processing constraints, such as illiteracy, they attach self-construed meanings to logos, colours, symbols, shapes, photos, and other visual elements of a product. Help within proximate social circles (e.g., children, other family members or friends with fewer constraints) is quite common in this case. How relatively literate family members help BOP consumers understand messages could lead to a rethinking of how to conceptualise the target 
audience, plan media channels and devise the messages. With the adoption of products and services, an understanding of this characteristic of the BOP target group may lead to a modified approach in marketing of products and services.

Private and public sector organisations need to exhibit care in the design and use of logos, colours, symbols, shapes, and photos so that BOP consumers can best decode the messages and can recognise and understand their products easily. For example, symbolic brand logos (e.g., such as the mobile banking company's bird symbol) seems to be easier for BOP consumers to recognise and attach meaning to, rather than a logo which contains text only. Though visual logos are more common in developed countries where brand building and brand equity management has a richer tradition, in many BOP countries products are often sold to consumers with text based descriptions. We found in the study that visual cues, brand names and packages (different sizes, different colours) can help the BOP consumers recognise and buy/use the product. Consequently, organisations in BOP markets ought to use more visual cues (different colours and different sizes) in their promotions so that BOP consumers can recognise and understand the benefits of their products more clearly. However, this needs to be traded off against the possibility of creating further confusion. For instance, organisations can use different colours to present different features or options of a product so that BOP consumers can easily understand the differences between different features or options of a product. Pictographic integration of product benefits in the product package and promotion in the local context (including the language) is the key managerial issue here. As low-literate BOP consumers cannot read the ingredient information from a product package, organisations can use different pictographic symbols to represent ingredients so that BOP consumers can more easily understand the ingredients of a product. However, this of course needs to be coupled with investment in brand building to facilitate that understanding through the development of associations to the brand. 
It should be noted that there are some ethical issues here also. One has to remember that marketing acts as a stimulus to demand. If BOP consumers are influenced by various marketing tactics to shift their expenditure from essential to non-essential products, in a world of free choice the results could be damaging to the poor. However, the products discussed here are so called pro-poor innovations (Ramani et al., 2012) so assist the poor.

Consumers in the BOP are largely a vulnerable market because of their limited education and lack of experience in evaluating marketing claims. In some cases, unethical and unscrupulous companies may somehow persuade this vulnerable group into buying their product. The hype created by marketing activities may have to be restrained by ethical marketers in their transactions with the BOP. The BOP consumer with his/her limited resources is not able to afford an inventory of products and buys only what s/he can consume on an immediate basis and hence comes the logic of single-served sachets by shampoo companies, for example. But it is also known that the additional packaging also means additional cost which is at the end of the day passed on to the customer only. If the poor are paying this cost, then is the poor not misled into thinking that smaller packages that look more affordable are in fact costing more on a per unit basis?

\section{Limitations and future research:}

One limitation of this study is that all interviewees were selected from Bangladesh. Visual comprehensibility is related to the literacy rate of a country. Therefore, some findings reported in this research may not be applicable in the context of another country. While our study is limited by its exploratory nature, it helps in providing an initial understanding of a relatively under-researched market. Therefore, though this research extends the research by Nakata and Weidner (2012), future research should test our findings, preferably quantitatively, first developing scales for visual comprehensibility, and then testing the 
relationship between visual comprehensibility and behavioural intention towards usage or usage of a product/ service in the BOP context. Also, future research on a large sample size would make the results more conclusive.

\section{Conclusion:}

The literature on consumer adoption of innovative pro-poor products and services within the BOP remains sparse because such markets have traditionally not been deemed to be economically viable. Such products and services have a distinct ability to improve the lives of BOP consumers and contribute to economic development through enhanced welfare. Despite some research which highlights the importance of visual comprehensibility very little research has collected data to understand this phenomenon better. This research contributes by identifying ways in which visual cues help BOP consumers to understand and use products and services better and the social nature of these product-to-consumer interactions. As an initial study in this area further research is necessary to elaborate on the findings here and to quantify them for different product categories and circumstances. 


\section{References:}

Arts, J. W. C., Frambach, R. T., and Bijmolt, T. H. A. (2011), “Generalizations on consumer innovation adoption: A meta-analysis on drivers of intention and behaviour”, International Journal of Research in Marketing, Vol. 28 No.2, pp.134-144.

Blumberg B, Cooper DR, Schindler PS (2014), Business Research Methods, 4th European Ed, McGraw Hill. ISBN: 9780077157487.

Boyatzis, R. E. (1998), Transforming qualitative information: Thematic analysis and code development, Sage.

Braun, V., and Clarke, V. (2006), "Using thematic analysis in psychology”, Qualitative research in psychology, Vol.3 No. 2, pp.77-101.

Bruner, G. C., and Kumar, A. (2005), “Explaining consumer acceptance of handheld Internet devices”, Journal of Business Research, Vol. 58 No. 5, pp.553-558.

Chikweche, T. and Fletcher, R. (2011), “Branding at the base of pyramid: a Zimbabwean perspective”, Marketing Intelligence \& Planning, Vol. 29 No.6, pp.247-263.

CIA (2013), “The World Factbook”, Available from: https://www.cia.gov/library/publications/the-world-factbook/ (accessed 12 June 2013).

Crilly, N., Moultrie, J. and Clarkson, P. J. (2004), “Seeing things: consumer response to the visual domain in product design”, Design Studies, Vol.25 No. 6, pp.547-577.

Davis, F. D. (1989), "Perceived usefulness, perceived ease of use, and user acceptance of information technology”, MIS Quarterly, PP.319-340.

Denzin, Norman K.; Lincoln, Yvonna S., eds. (2005), The Sage Handbook of Qualitative Research (3rd ed.), Thousand Oaks, CA: Sage. ISBN 0-7619-2757-3. 
Dowell, D., Heffernan, T. and Morrison, M. (2013), “Trust formation at the growth stage of a business-to-business relationship: A qualitative investigation”, Qualitative Market Research: An International Journal, Vol. 16 No. 4, pp.436-451.

Eifert, B., Gelb, A. and Ramachandran, V. (2005), “Business Environment and Comparative Advantage in Africa: Evidence from the Investment Climate Data”, World Bank working paper series, The World Bank, Washington, DC, pp. 195-233.

Fishbein, M. and Ajzen, I. (1975), “Belief, attitude, intention and behavior: An introduction to theory and research”, Reading, MA: Addison- Wesley.

Frith, H., and Gleeson, K. (2004), “Clothing and Embodiment: Men Managing Body Image and Appearance”, Psychology of Men \& Masculinity, Vol.5 No. 1, pp. 40.

Gatignon, H. and Robertson, T. S. (1985), “A propositional inventory for new diffusion research”, Journal of Consumer Research, Vol. 11 No. 4, pp. 849-867.

Hammond, A. L., and Prahalad, C. K. (2004), "Selling to the poor". Foreign Policy, VOL.142, pp.30-37.

Havelock, E. A. (1978), The Greek concept of justice: From its shadow in Homer to its substance in Plato. Cambridge: Harvard University Press.

Hayes, N. (2000), Doing psychological research, Taylor \& Francis Group.

Heckler, S. E., Childers, T. L., and Houston, M. J. (1993), “On the construct validity of the SOP scale”, Journal of Mental Imagery, Vol. 17 No. 3, pp.119-32.

Hoeffler, S. (2003), “Measuring preferences for really new products”, Journal of Marketing Research, Vol. 40 No. 4, pp. 406-420.

Johnson, S., Ostry, J. and Subramanian, A. (2007), “The prospects for sustained growth in Africa: benchmarking the constraints”, IMF Working Paper No. 07/52, IMF, Washington, DC. 
Lowe, B., and Alpert, F. (2015), “Forecasting consumer perception of innovativeness”, Technovation, In press, published online $6^{\text {th }}$ March, 2015, doi:

10.1016/j.technovation.2015.02.001

Lowe, B., Lynch, D. and Lowe, J. (2014), “The role and application of social marketing in managing water consumption: a case study”, International Journal of Nonprofit and Voluntary Sector Marketing, Vol. 19 No. 1, pp.14-26.

Malhotra, N. K. (2004), Marketing Research: An Applied Orientation. 4th Edition. New Jersey: Pearson Education.

Meuter, M. L., Bitner, M. J., Ostrom, A. L., and Brown, S. W. (2005), “Choosing among alternative service delivery modes: An investigation of customer trial of self-service technologies”, Journal of Marketing, Vol. 69 No.2, pp. 61-83.

Nakata, C., and Weidner, K. (2012), “Enhancing New Product Adoption at the Base of the Pyramid: A Contextualized Model,” Journal of Product Innovation Management”, Vol. 29 No.1, pp. 21-32.

Nwanko, S. (2000), “Assessing the marketing environment in sub-Saharan Africa: opportunities and threats analysis”, Marketing Intelligence and Planning, Vol. 18 No. 3, pp. 144-513.

Ostlund, L. E. (1974) "Perceived innovation attributes as predictors of innovativeness”, Journal of Consumer Research, Vol. 1 No. 2, pp. 23-29.

Payaud, M. A. (2014), “Marketing strategies at the bottom of the pyramid: Examples from Nestle, Danone, and Procter \& Gamble”, Global Business and Organizational Excellence, Vol. 33 No. 2, pp. 51-63.

Plouffe, C. R., Hulland, J. S., and Vandenbosch, M. (2001), "Research Report: Richness Versus Parsimony in Modeling Technology Adoption Decisions-Understanding 
Merchant Adoption of a Smart Card-Based Payment System”, Information Systems Research, Vol. 12 No. 2, pp. 208-222.

Prahalad, C K (2005), Fortune at the bottom of the pyramid: Eradicating poverty through profits, Upper Saddle River, NJ: Wharton School Publishing.

Prahalad, C K (2010), Fortune at the bottom of the pyramid: Eradicating poverty through profits, Upper Saddle River, NJ: Wharton School Publishing.

Rahman, M., Floyd, D., and Hasan, M. R. (2013), "Brand Orientation as a Strategy That Influences the Adoption of Innovation in the Bottom of the Pyramid Market.” Strategic Change, Vol. 22 No.3/4, pp. 225-239. doi:10.1002/jsc

Ramani, S. V., SadreGhazi, S., and Duysters, G. (2012), “On the diffusion of toilets as bottom of the pyramid innovation: Lessons from sanitation entrepreneurs”, Technological Forecasting and Social Change, Vol. 79 No. 4, pp. 676-687.

Rogers, E. M. (2003), Diffusion of innovations (5th ed.), New York: Free Press.

Sayre, S. (2001), Qualitative methods for marketplace research, Thousand Oaks, CA: Sage.

Sey, A., Lowe, B., and Poole, N. (2010), “The use of intellectual property protection by micro, small, and medium-scale enterprises: a case study of Ghana,” Enterprise Development and Microfinance, Vol. 21 No. 1, pp. 67-83.

Shih, C. F., and Venkatesh, A. (2004), “Beyond adoption: development and application of a use-diffusion model”, Journal of Marketing, Vol.68 No.1, pp. 59-72.

Tornatzky, L. G., and Klein, K. (1982), “Innovation characteristics and innovation adoptionimplementation: A meta-analysis of findings”, IEEE Transactions on engineering management, Vol. 29 No. 1.

Touzani, M., Fatma, S., and Mouna-Meriem, L. (2015), “Country-of-origin and emerging countries: revisiting a complex relationship”, Qualitative Market Research: An International Journal, Vol.18 No.1, pp. 48-68. doi:10.1108/QMR-04-2012-0019 
Viswanathan, M., Rosa, J. A., and Harris, J. E. (2005), “Decision making and coping of functionally illiterate consumers and some implications for marketing management”, Journal of Marketing, Vol. 69 No.1, pp.15-31.

World Bank (2013), Bangladesh Data, Available from: http://data.worldbank.org/country/bangladesh (accessed 7April 2015).

World Resources Institute (2007), The Next 4 Billion- Market Size \& Business Strategy in the Base of the Pyramid, Washington DC.

Zikmund, William, Steve D’Alessandro, Hume Winzar, Ben Lowe and Barry Babin (2014), Marketing Research: $3^{\text {rd }}$ Asia Pacific Edition, Melbourne: Cengage Learning. ISBN978-0170236027. 
Table 1: Respondents

\begin{tabular}{|l|l|l|}
\hline No & Type of respondents & $\begin{array}{l}\text { Product or } \\
\text { Service Category }\end{array}$ \\
\hline R1 & Head of Marketing & $\begin{array}{l}\text { Toiletries } \\
\text { Products }\end{array}$ \\
\hline R2 & $\begin{array}{l}\text { Head of FIXED Broadband Internet and } \\
\text { Broadband Commercial Division }\end{array}$ & $\begin{array}{l}\text { Community } \\
\text { Information } \\
\text { Centre (CIC) }\end{array}$ \\
\hline R3 & Junior Consultant & IT based Services \\
\hline R4 & Senior Officer, Events and Activation & Mobile Banking \\
\hline R5 & General Manager & Food Products \\
\hline R6 & Deputy General Manager & Micro Insurance \\
\hline R7 & Entrepreneur & IT based Services \\
\hline R8 & Entrepreneur & IT based Services \\
\hline R9 & Customer & IT based Services \\
\hline R10 & Customer & IT based Services \\
\hline R11 & Customer & $\begin{array}{l}\text { Mobile Banking } \\
\text { Service }\end{array}$ \\
\hline
\end{tabular}




\section{Table 2: Interview Guideline}

\begin{tabular}{|c|c|}
\hline Respondents & $\begin{array}{l}\text { Indicative questions approach related to visual } \\
\text { comprehensibility }\end{array}$ \\
\hline \multirow{6}{*}{$\begin{array}{l}\text { Senior managers, } \\
\text { Consultants, } \\
\text { Entrepreneurs }\end{array}$} & $\begin{array}{l}\text { How do low-literate or illiterate consumers recognise your company's } \\
\text { brand or product? }\end{array}$ \\
\hline & How do they understand the use of this product? \\
\hline & $\begin{array}{l}\text { How do you overcome reading and writing difficulties faced by } \\
\text { consumers of your products? }\end{array}$ \\
\hline & $\begin{array}{l}\text { Do you think that visual cues can influence the adoption of this } \\
\text { product? In what way? }\end{array}$ \\
\hline & What types of visual cues can influence the adoption of this product? \\
\hline & How can these visual cues influence their adoption? \\
\hline \multirow{5}{*}{ BOP Consumers } & Can you please tell me what you know about this product? \\
\hline & $\begin{array}{l}\text { How do you recognise this product or understand the use of this } \\
\text { product? }\end{array}$ \\
\hline & $\begin{array}{l}\text { Do pictures, symbols, shapes, and colours of this product help you to } \\
\text { recognise or understand this product or organisation? }\end{array}$ \\
\hline & $\begin{array}{l}\text { What does this symbol mean to you? Does it help you to understand } \\
\text { and use the product? }\end{array}$ \\
\hline & $\begin{array}{l}\text { Does any other element of this product help you to recognise or } \\
\text { understand this product? }\end{array}$ \\
\hline
\end{tabular}

